Gut, 1978, 19, 1043-1048

\title{
Measurement of fasting and postprandial plasma VIP in man
}

\author{
S. J. MITCHELL AND S. R. BLOOM1 \\ From the Department of Nuclear Medicine, Thorn Institute of Clinical Science, Middlesex Hospital \\ Medical School, London, and the Department of Medicine, Royal Postgraduate Medical School, \\ Hammersmith Hospital, London
}

SUMMARY A specific radioimmunoassay has been developed capable of detecting $1.5 \mathrm{pmol}$ VIP/1 plasma with $95 \%$ confidence. The antisera employed reacted most avidly with whole VIP, partly with $\mathrm{C}$ terminal, but not with $\mathrm{N}$ terminal fragments. In 110 healthy fasting volunteers plasma VIP concentrations were estimated to lie between 0.5 and $21 \mathrm{pmol} / 1$ (median 1.7). No significant change was seen after ingestion of a standard test meal.

Vasoactive intestinal peptide (VIP) is a basic polypeptide composed of 28 amino acids (Bodanszky et al., 1973) and shares many homologies with the classical hormones secretin and glucagon (Bodanszky et al., 1973). It was isolated from the hog small intestine by Said and Mutt in 1970 and is widely distributed throughout the intestine in a single major molecular form (Bloom and Bryant 1973). It has recently been found in significant quantities in many other tissues including the central nervous system and has been proposed as a possible neurotransmitter (Bryant et al., 1976). Its range of pharmacological actions includes inhibition of gastric acid production (Barbezat and Grossman, 1971), stimulation of alkaline pancreatic juice flow (Said and Mutt, 1972), stimulation of myocardial contractility (Said and Mutt, 1972), and glycogenolysis (Kerins and Said, 1973). In addition, it causes a significant increase in mucosal cyclic AMP concentration (Schwartz et al., 1974) and small intestinal juice production (Barbezat et al., 1971).

It was first implicated in the Verner-Morrison syndrome after the finding of high circulating levels of VIP as well as large amounts of extractable VIP in the tumours of these patients (Bloom et al., 1973). A sensitive assay for the measurement of plasma levels has been developed to study the physiology and pathology of VIP.

\footnotetext{
${ }^{1}$ Address for correspondence: Dr S. R. Bloom, Department of Medicine, Hammersmith Hospital, Du Cane Road, London W12.
}

Received for publication 26 May 1978

\section{Methods}

Antisera to pure porcine VIP were produced in rabbits by multiple subcutaneous injections of 100 $\mathrm{nmol} / \mathrm{rabbit}$ VIP, conjugated to $50 \mathrm{nmol}$ bovine serum albumin (BSA) by carbodiimide condensation, emulsified in complete Freund's adjuvant. Boost injections were given at three monthly intervals and antisera harvested between one and two years. Synthetic VIP fragments 1-6, 1-18, 1-22, $7-28,11-28$, and $18-28$, pure chicken VIP and an extract of human VIPoma were used to assess antisera binding characteristics.

Incorporation of $0 \cdot 7-1 \cdot 1$ nmol 125I IMS 30 Amersham (approx 2MCi/mol) into $6 \mathrm{nmol}$ pure porcine VIP in $50 \mathrm{mmol} / 1$ acetate buffer at $\mathrm{pH} 5.0$ was acheived by incubating with 22 pmol lactoperoxidase (Sigma milk derived) and $1.8 \mathrm{nmol}$ $\mathrm{H}_{2} \mathrm{O}_{2}$ at room temperature for 15 minutes in a total volume of $130 \mu$. The ${ }^{125}$ I VIP was purified on CM Sephadex C25 column $(1.5 \times 30 \mathrm{~cm})$ at $4^{\circ} \mathrm{C}$ over 36 hours, using $160 \mathrm{mmol} / \mathrm{l}$ phosphate buffer at pH 8.5 containing $0.4 \mathrm{mmol} / 1$ human albumin (Lister Institute) and $0.4 \mathrm{MKIU} / 1$ aprotinin (Trasylol) as the eluent.

Blood samples were taken with $20 \mathrm{KU} / 1$ heparin and $0.5 \mathrm{MKIU} / 1$ aprotinin, centrifuged immediately, and the decanted plasma stored at $-20^{\circ} \mathrm{C}$ until assay. The stability of exogenous porcine VIP added to three fresh plasmas $(50 \mathrm{pmol} / \mathrm{l})$ was tested by incubation, in presence or absence of aprotinin, at room temperature for between one and 24 hours. Estimations of endogenous VIP content in plasmas 
from four patients with a VIPoma (80 to 450 pmol/l) were compared in two aliquots, one being left at $-20^{\circ} \mathrm{C}$ undisturbed for six months and the other being briefly thawed at $18^{\circ} \mathrm{C}$ and refrozen on three occasions during this time.

Assay tubes were set up in duplicate, each with $200 \mu \mathrm{l}$ unknown plasma and $600 \mu \mathrm{l}$ of $50 \mathrm{mmol} / \mathrm{l}$ phosphate buffer, $\mathrm{pH} 7.0$, containing antibody (1:320,000 dilution) and 1 fmol VIP ${ }^{125}$ I and incubated for four days at $4^{\circ} \mathrm{C}$. Separation of bound antibody from free VIP ${ }^{125}$ I was effected by addition of $26 \mathrm{mg} /$ tube charcoal suspension (Norit GSX, Hopkins \& Williams Ltd) in $0.5 \mathrm{ml}$ buffer containing $2.6 \mathrm{mg}$ dextran (Fig. 1). The standard curve was made by addition of varying quantities of a pure natural porcine VIP standard to VIP-free plasma. VIP standards were prepared gravimetrically (Cahn Electrobalance). The VIP was then dissolved in a protein-containing solution $(0.14 \mathrm{~mol} / \mathrm{l}$ lactose, $0.4 \mathrm{mmol} / 1 \mathrm{BSA}, 11 \mathrm{mmol} / 1$ citric acid, $6 \mathrm{mmol} / 1$ cysteine $\mathrm{HCl}$, and $1 \mathrm{MKIU} / 1$ aprotinin in 100 $\mathrm{mmol} / \mathrm{l}$ formic acid), lyophilised in aliquots; sealed in vacuum and stored at $-20^{\circ} \mathrm{C}$.

Hormone-free plasma was prepared from pooled, freshly collected plasma using specific immunoabsorption with high titre VIP antisera coupled to

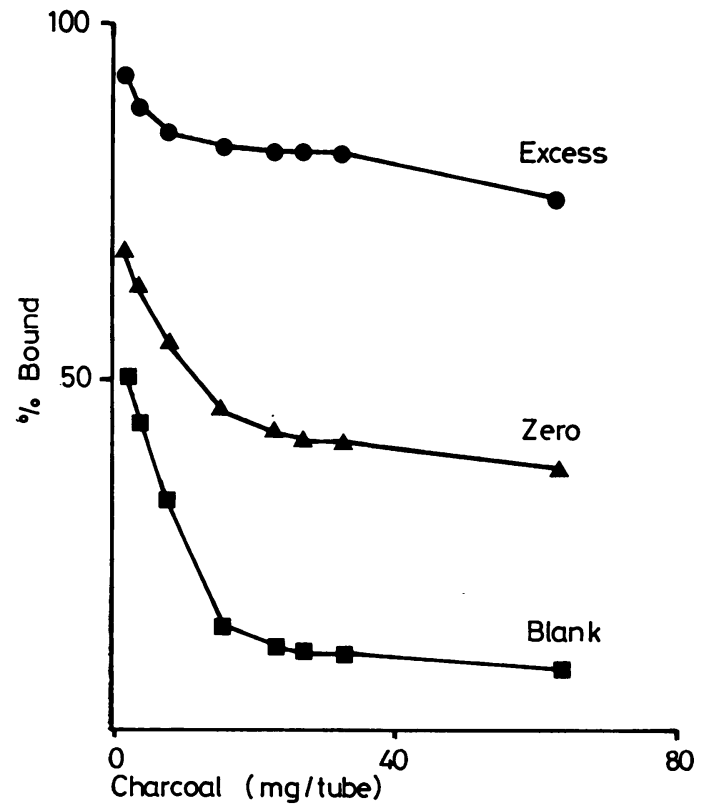

Fig. 1 Effect of increasing additions of charcoal after assay incubation, to separate free from antibody bound VIP ${ }^{125} I$, on the binding by excess antiserum, binding at optimal titre in the absence of unlabelled peptide and non-specific binding in the absence of antiserum. cyanogen bromide activated Sepharose beads (Pharmacia Ltd). Six millilitres of VIP antiserum (titre 1:64,000) was coupled to $20 \mathrm{ml}$ wet Sepharose beads and used to treat $100 \mathrm{ml}$ plasma (Alford et al., 1977). Very thorough washing of the beads immediately before use prevented contamination of the plasma with any free VIP antibody. The activity of the beads was checked by demonstrating complete removal of $500 \mathrm{pmol} / 1$ of added exogenous VIP. The plasma VIP content was unaffected by treatment with Sepharose beads prepared using non-VIP antisera.

To establish a normal range, plasma samples from 110 healthy fasting volunteers (mean age 29 years, range 18-40 years) were assayed. The plasma VIP response to a test meal ( $79 \mathrm{~g}$ carbohydrate, $28 \mathrm{~g}$ protein, and $44 \mathrm{~g}$ fat) was tested in a further 10 subjects. Gastrin concentrations were also estimated for reference purposes using a previously described radioimmunoassay system (Russell et al., 1976).

\section{Results}

Only $10 \%$ of the 200 rabbits immunised over a four year programme produced a significant titre of antibodies to VIP. Of these only two, V9 and V25, were of sufficient affinity to be useful for plasma radioimmunoassay, both being useable at a dilution of $1: 400,000(50 \%$ binding point with 1 fmol VIP ${ }^{125} \mathrm{I}$ in $0.8 \mathrm{ml}$ buffer). Binding was reduced to $40 \%$ by addition of 7 and $12 \mathrm{pmol} / 1$ VIP with antiserum V9 and V25 respectively. The displacement by VIP fragments 18-28 and 7-28 is shown in Fig. 2 and the other fragments, chicken and human VIP, in Table 1. While antiserum V25 reacts well with $C$ terminal fragments, antiserum V9 reacts fully only with whole VIP. Both react equally with human VIP. Neither showed any displacement on addition of $500 \mathrm{nmol} /$ assay tube of glucagon, secretin, gastrin, motilin, cholecystokinin, or gastric inhibitory peptide. Antiserum V9 was used for all assays subsequently both because of its minimal reaction with VIP fragments and its greater sensitivity, allowing changes of $1.5 \mathrm{pmol} / 1$ plasma VIP $(0.3 \mathrm{fmol} /$ tube $)$ to be distinguished with $95 \%$ confidence (Fig. 3 ).

During iodination approximately $60 \%$ of the added ${ }^{125}$ I reacted with $10 \%$ of the VIP. Clear separation of the iodinated tracer from other iodinated products (Fig. 4), including diiodinated VIP and non-iodinated VIP, allowed preparation of a stable monoiodinated tracer with a specific activity of between 1.6 and $2.0 \mathrm{MCi} / \mathrm{mol}$, identical specific activity values being obtained when calculated either by self displacement or stoichiometrically. Stored at $-20^{\circ} \mathrm{C}$ the label was usable up to four months.

No significant loss of exogenous porcine VIP in the three fresh plasma samples was observed over a 


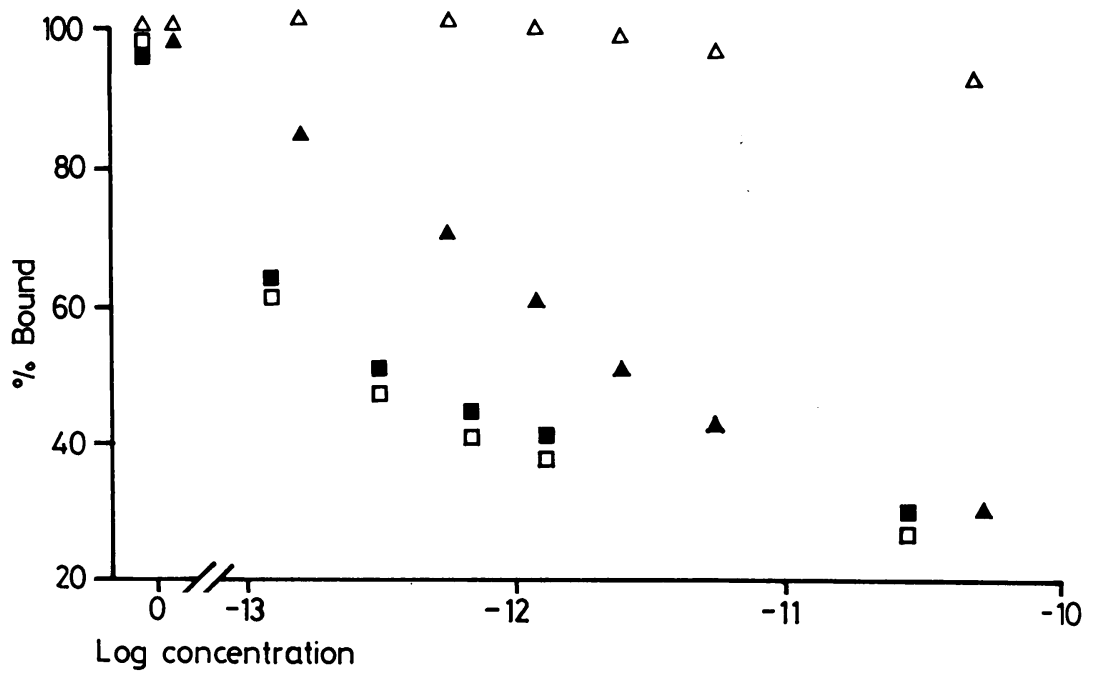

Fig. 2 Displacement curves of VIP fragment 7-28 (squares) and VIP fragment 18-28 (triangles) for antisera V9 (open symbols) against V25 (closed symbols). The percentage of zero point binding is represented on the vertical axis. Concentration is given as mol/assay tube.

four hour period at room temperature in the presence of aprotinin (Table 2). A loss in endogenous VIP content between $20-35 \%$ was found after repeated freezing and thawing of the plasma samples from VIPoma patients. The freeze-dried standards were stable (loss less than $5 \%$ ) for more than three years when tested at regular intervals against freshly prepared porcine VIP standards.

The measured plasma VIP concentrations in 110 normal subjects showed a skew distribution ranging from $0 \cdot 5$ to $21 \mathrm{pmol} / 1$ with a mean of $2 \cdot 1$, mode of 1.5 and the median of 1.7 (Fig. 5). No significant rise of VIP was seen after the meal (Fig. 6), unlike the considerable rise in plasma gastrin.

Table 1 Binding characteristics of antisera $V 9$ and V25 with VIP fragments and other forms of VIP

\begin{tabular}{lrr}
\hline VIP Type & $V 9$ & \multicolumn{1}{c}{$V 25$} \\
\hline $1-6$ & $>5 \times 10^{-9}$ & $>5 \times 10^{-9}$ \\
$1-18$ & $6 \times 10^{-10}$ & $9 \times 10^{-11}$ \\
$1-22$ & $1 \times 10^{-11}$ & $3 \times 10^{-12}$ \\
$7-28$ & $2 \times 10^{-13}$ & $3 \times 10^{-18}$ \\
$11-28$ & $9 \times 10^{-18}$ & $5 \times 10^{-12}$ \\
$18-28$ & $6 \times 10^{-8}$ & $2 \times 10^{-12}$ \\
Chicken & $5 \times 10^{-10}$ & $>5 \times 10^{-10}$ \\
Human & $2 \times 10^{-11}$ & $3 \times 10^{-11}$ \\
(Crude tumour extract) & $5 \times 10^{-16}$ & $9 \times 10^{-14}$ \\
Porcine & & \\
\hline
\end{tabular}

Figures indicate mol/assay tube which cause $50 \%$ displacement of porcine VIP ${ }^{125}$ I from the antibody at normal working dilution and four days incubation. The VIP content of crude human tumour extract is on an arbitrary basis only and is shown solely for comparison of the two antisera.

\section{Discussion}

In contrast to the other hormonal peptides in the secretin-glucagon group, VIP is only weakly anti-

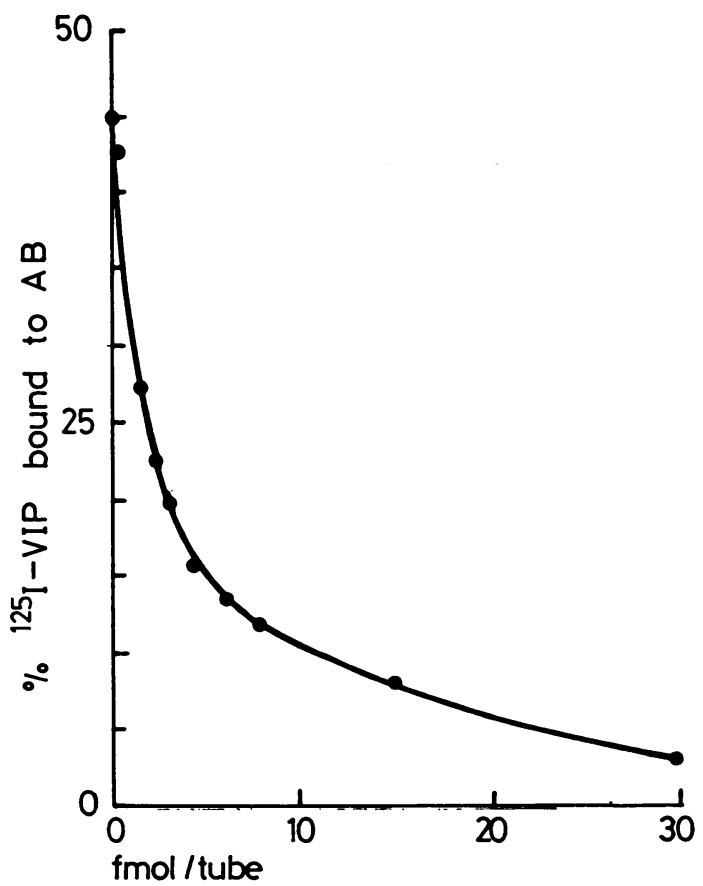

Fig. 3 Standard displacement curve obtained using antiserum $V 9$. 


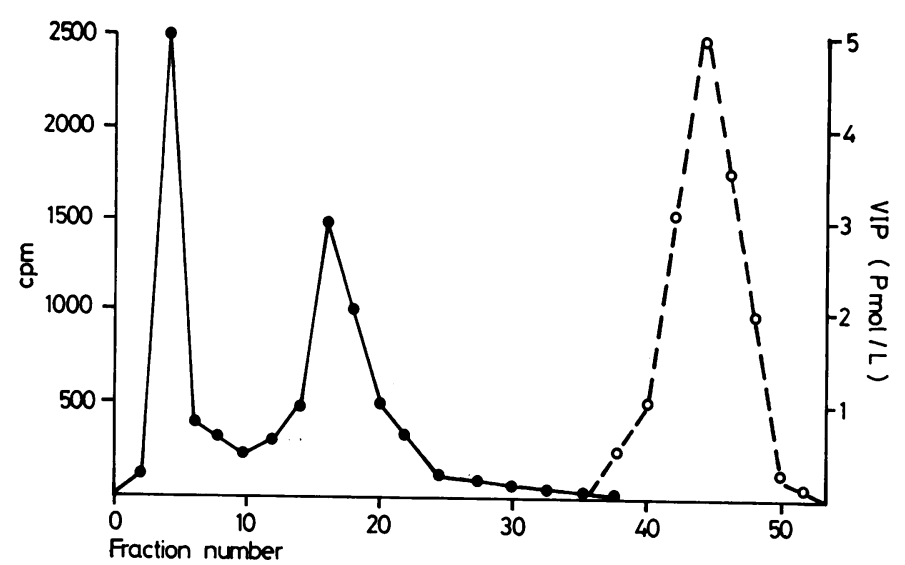

Fig. 4 Elution pattern of crude VIP iodination reaction product from CM Sephadex C25 ion exchange column $(K 15 / 30)$. The elution buffer was 0.16 mol/l phosphate at pH 8.5 and was collected in $3 \mathrm{ml}$ fractions run at a rate of $5 \mathrm{ml} / \mathrm{h}$. The iodination product had 100 pmol cold pure porcine VIP added immediately before ion exchange to act as a marker. Non-iodinated VIP measured by radioimmunoassay is shown as dotted lines, while the eluted radioactive product is shown as solid lines, the first peak being ${ }^{125} I$ and the second VIP ${ }^{125} I$.

Table 2 Stability of added pure porcine VIP (50 pmol/l) at room temperature in the presence or absence of aprotinin in three fresh plasmas from fasting healthy volunteers

\begin{tabular}{lll}
\hline Incubation conditions & \multicolumn{2}{c}{ Mean \% loss } \\
\cline { 2 - 3 } & With aprotinin & Without aprotinin \\
\hline Frozen immediately & 0 & 0 \\
Room temperature (h) & 0 & 15 \\
1 & 0 & 30 \\
4 & 5 & 40 \\
12 & 16 & 42 \\
\hline
\end{tabular}

genic, which is surprising for such a strongly charged molecule, making difficult the development of high affinity antisera. Iodination, however, presented few problems as VIP has two tyrosine residues. Although possessing no tryptophan, the presence of a methionine residue at position 17 renders VIP susceptible to oxidative damage. Thus the use of a trace iodination technique followed by separation of the pure monoiodinated VIP by high resolution ion exchange chromatography not only avoided significant oxidative damage but also gave a uniform iodination

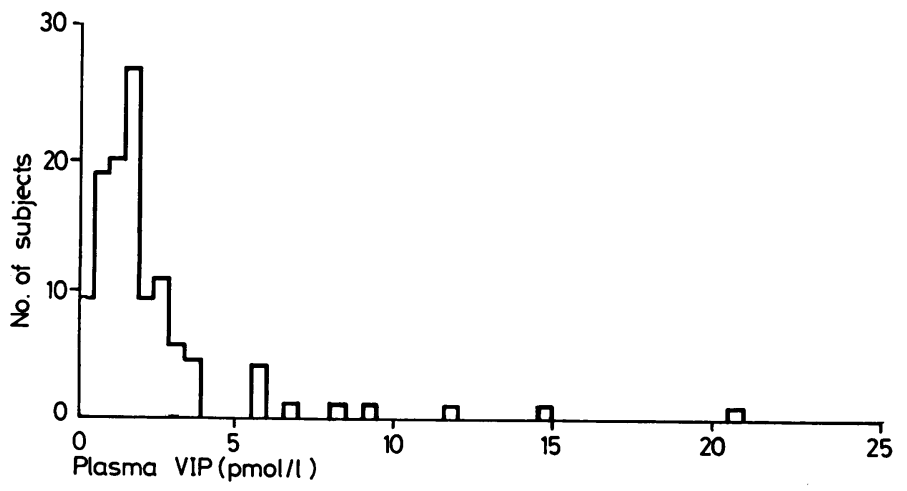

Fig. 5 Plasma VIP concentrations in 110 healthy fasting subjects. 


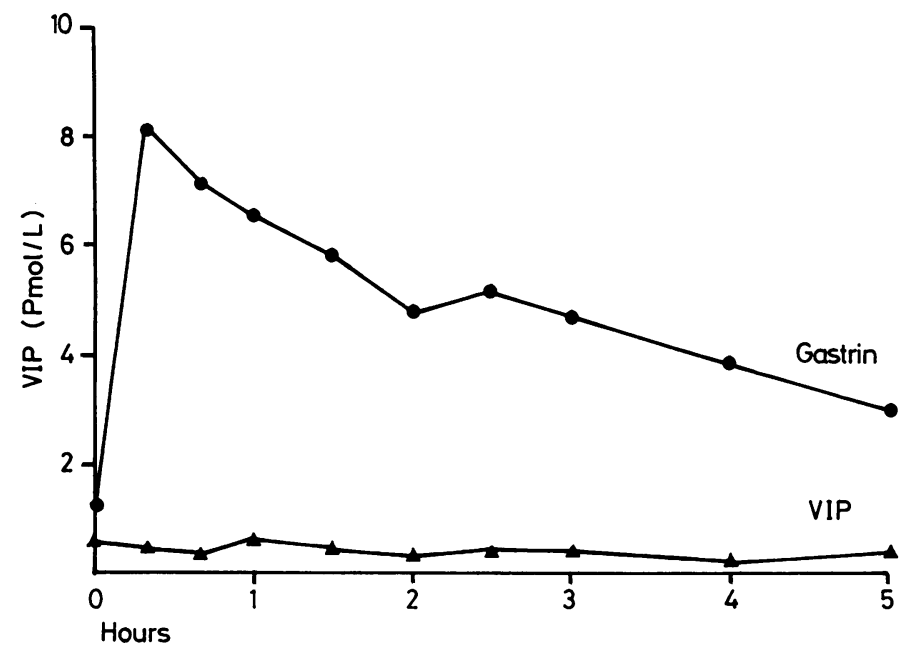

Fig. 6 Response of plasma radioimmunoassayable gastrin and VIP to ingestion of a standard lunch in 10 healthy volunteers.

product of high specific activity. When stored in a dilute protein solution at $-20^{\circ} \mathrm{C}$ the label showed little change in binding characteristics over many months.

VIP in plasma samples was readily degraded at room temperature and this could not be completely prevented by addition of aprotinin. Care was therefore taken to deep freeze samples within 15 minutes of venepuncture and to avoid repetitive freezing and thawing. Stability of the VIP standards was ensured by storing them lyophilised in mass-produced single use vials.

Human VIP has not yet been isolated, raising the possibility of a species difference between human and porcine VIP. The variation between chicken and porcine VIP is small, though easily detected by the antisera tested here, however, with alterations in only four amino acids (Nilsson, 1975). Human and porcine VIP migrate in identical positions on gel columns, show parallel dilution curves in radioimmunoassay, and cross-react equally with porcine antisera of varying specificity. It thus seems unlikely that they have significant differences in their amino acid sequence. It was also of interest that when crude extracts of human ileum were subjected to gel chromatography only a single major peak of VIP immunoreactivity was detected (Bryant et al., 1976) thus excluding the possibility of any significant cross-reaction with our assay of any, as yet undiscovered, gut hormonal peptides.

The fasting level of plasma VIP is very low and many normal subjects have concentrations below the individual $95 \%$ confidence limit of the assay. In patients with watery diarrhoea resulting from the presence of a VIP-producing tumour, plasma levels are in excess of $50 \mathrm{pmol} / 1$ (Bloom, 1978). Therefore with this assay there is no problem in reliably excluding excessive circulating VIP as the cause of active diarrhoea. The reason for the higher values reported by others (Said and Mutt, 1972; Ebeid et al., 1976) is unknown but may relate to greater sensitivity of this assay, which reduces the influence of interference by non-specific plasma effects and also to the low reactivity with VIP fragments. The physiological role of VIP is still unknown and this is emphasised by the failure to find a change in circulating concentrations after a meal. VIP is found in larger quantities in the gut than any other of the gastrointestinal hormonal peptides so far described. It is also found in almost all other tissues of the body and its localisation in neurones of the central nervous system and in fine nerve fibres in the periphery suggests a role as a peptidergic neurotransmitter. The origin and importance of VIP in the circulation is thus uncertain and it may conceivably be merely an overflow of VIP acting locally in various tissues. The plasma concentration may thus reflect the sum of a wide variety of different activities in different organs.

This work was dependent on pure porcine and chicken VIP which was supplied by Professor V. Mutt, Stockholm, and synthetic VIP fragments which were supplied by Professor Yanihara, Japan, for which we are most grateful. The work was supported by the Wellcome Trust and Medical Research Council. 


\section{References}

Alford, F. P., Bloom, S. R., and Nabarro, J. D. N. (1977). Glucagon levels in normal and diabetic subjects: use of specific immunoabsorbent for glucagon radioimmunoassay. Diabetologia, 13, 1-6.

Barbezat, G. O., and Grossman, M. I. (1971). Intestinal secretion: stimulation by peptides. Science, 174, 422-423.

Bloom, S. R. (1978). VIP and watery diarrhoea. In Gut Hormones, pp. 583-588. Edited by S. R. Bloom. Churchill Livingstone.

Bloom, S. R. and Bryant, M. G. (1973). The distribution of vasoactive intestinal peptide (VIP) in the primate gastrointestinal tract and characterisation of VIP from human tumours (Abstract). Gut, 14, 823.

Bloom, S. R., Polak, J. M., and Pearse, A. G. E. (1973). Vasoactive intestinal peptide and watery diarrhoea syndrome. Lancet, 2, 14-16.

Bodanszky, M., Klausner, Y. S., and Said, S. I. (1973). Biological activities of synthetic peptides corresponding to fragments of and to the entire sequence of the vasoactive intestinal peptide. Proceedings of the National Academy of Sciences (Wash), 70, 382-384.

Bryant, M. G., Bloom, S. R., Polak, J. M., Albuquerque, R. H., Modlin, I. M., and Pearse, A. G. E. (1976). Possible dual role for vasoactive intestinal peptide as gastrointestinal hormone and neurotransmitter substance. Lancet, 1, 991-993.

Ebeid, A. M., Murray, P., Hirsch, H., Wesdorp, R. I. C., and Fischer, J. E. (1976). Radioimmunoassay of vasoactive intestinal peptide. Journal of Surgical Research, 20, 355360.

Kerins, C., and Said, S. I. (1973). Hyperglycemic and glycogenolytic effects of vasoactive intestinal polypeptide. Proceedings of the Society of Experimental Biology $(N Y)$, 142. 1014-1017.

Nilsson, A. (1975). Structure of the vasoactive intestinal octacosapeptide from chicken intestine. The amino acid sequence. FEBS Letters, 60, 322-326.

Russell, R. C. G., Bloom, S. R., Fielding, L. P., and Bryant, M. G. (1976). Current problems in the measurement of gastrin release. A reproducible measure of physiological gastrin release. Postgraduate Medical Journal, 52, 645-650.

Said, S. I., and Faloona, G. R. (1975). Elevated plasma and tissue levels of vasoactive intestinal polypeptide in the watery-diarrhea syndrome due to pancreatic, bronchogenic and other tumors. New England Journal of Medicine, 293, 155-160.

Said, S. I., and Mutt, V. (1970). Polypeptide with broad biological activity: isolation from small intestine. Science, 169, 1217-1218.

Said, S. I., and Mutt, V. (1972). Isolation from porcine intestinal wall of a vasoactive octacosapeptide related to secretin and to glucagon. European Journal of Biochemistry, 28, 199-204.

Schwartz, C. J., Kimberg, D. V., Sheerin, H. E., Field, M., and Said, S. I. (1974). Vasoactive intestinal peptide stimulation of adenylate cyclase and active electrolyte secretion in intestinal mucosa. Journal of Clinical Investigation, 54, 536-544. 